\title{
Rising to the challenge of multimorbidity
}

\author{
(c) (1) (\$)
}

We need to combine generalist and specialist skills

\section{Christopher J M Whitty chief medical officer for England ${ }^{1}$, Carrie MacEwen chair ${ }^{2}$, Andrew Goddard president $^{3}$, Derek Alderson president ${ }^{4}$, Martin Marshall chair ${ }^{5}$, Catherine Calderwood chief medical officer for Scotland ${ }^{6}$, Frank Atherton chief medical officer for Wales ${ }^{7}$, Michael McBride chief medical officer for Northern Ireland ${ }^{8}$, John Atherton co-chair ${ }^{9}$, Helen Stokes-Lampard former chair ${ }^{5}$, Wendy Reid medical director ${ }^{10}$, Stephen Powis national medical director ${ }^{11}$, Clare Marx chair $^{12}$}

\footnotetext{
${ }^{1}$ Department of Health and Social Care, London, UK; ${ }^{2}$ Academy of Medical Royal Colleges, London, UK; ${ }^{3}$ Royal College of Physicians, London, UK; ${ }^{4}$ Royal College of Surgeons, London, UK; ${ }^{5}$ Royal College of General Practitioners, London, UK; ${ }^{6}$ Scottish Government, Edinburgh, UK; ${ }^{7}$ Welsh Government, Cardiff, UK; ${ }^{8}$ Department of Health, Belfast, UK; ${ }^{9}$ Medical Schools Council, London, UK; ${ }^{10} \mathrm{Health}$ Education England, London, UK; ${ }^{11} \mathrm{NHS}$ England, London, UK; ${ }^{12}$ General Medical Council, London, UK
}

Life expectancy has improved remarkably over the past four decades thanks to improved medical and public health practice based on advances in science. Greater specialisation in medical sciences and by the clinical teams delivering care has contributed to improved clinical outcomes, and many more people are enjoying life relatively unaffected by disease from early childhood through to beyond retirement age.

The proportion of patients who have two or more medical conditions simultaneously is, however, rising steadily. This is currently termed multimorbidity, although patient groups prefer the more intuitive "multiple health conditions." In high income countries, multimorbidity is mainly driven by age, ${ }^{2}$ and the proportion of the population living with two or more diseases is steadily increasing because of demographic change. This trend will continue.

Multimorbidity is, however, not restricted to older citizens. Being less advantaged socioeconomically accelerates the process, so in deprived areas multimorbidity occurs earlier in life. ${ }^{3}$ Children or young adults with serious congenital or acquired impairments often have multiple physical or mental illnesses, ${ }^{4}$ and the interaction between mental and physical health makes each harder to treat. ${ }^{5}$ Certain periods of life, including pregnancy, increase the probability that multiple conditions will present simultaneously. Although this transition is happening most rapidly in industrialised countries, it is already increasing in middle income countries and will become a global problem. ${ }^{6}$

The multimorbidity trend presents challenges to the entire medical profession, from general practice and community care to acute and long term hospital settings. Greater specialisation, especially for hospital based doctors, has improved our ability to treat single diseases, but unless we react to the increase in multimorbidity it will disadvantage the increasing proportion of patients with multiple seemingly unrelated diseases.

Treating each disease in a patient as if it exists in isolation will lead to less good outcomes and complicate and duplicate interactions with the healthcare system. ${ }^{7}$ Training from medical school onwards, clinical teams, and clinical guidelines, however, all tend to be organised along single disease or single organ lines. As a result, a single patient may take multiple drugs recommended by different guidelines and see several specialists treating subcomponents of their overall health problem in isolation. Medical science is also disease based. Clinical trials still often exclude people who have more than one condition. Good vertical integration exists from bench to bedside for a single condition or disease, but there is little or no horizontal integration between diseases that often coexist. ${ }^{8}$ This will require an intellectual shift and rethinking some elements of our research, training, and practice in virtually every discipline.

\section{Cluster medicine}

The shift includes moving from thinking about multimorbidity as a random assortment of individual conditions to recognising it as a series of largely predictable clusters of disease in the same person. Some of these clusters will occur by chance alone because individuals are affected by a variety of commonly occurring diseases. Many, however, will be non-random because of common genetic, behavioural, or environmental pathways to disease. Identifying these clusters is a priority and will help us to be more systematic in our approach to multimorbidity. 
All doctors know the clusters of disease around smoking, diabetes, HIV, or obesity. Known clusters affect multiple organs with multiple pathological processes. The cluster around diabetes is a good example, with the common serious disease affecting the heart, nervous system, skin, peripheral vasculature, and eyes. Diabetologists already provide care for the cluster of multiorgan diseases around diabetes, and some specialties, such as geriatrics or general practice, have multimorbidity at their heart. For most, however, training and service organisation are not optimised to face a multimorbidity dominated future.

Bringing together the undoubted benefits of specialism with a more systematic approach to the realities of dealing with patients with multiple diseases is possible but will not happen spontaneously. It is possible and desirable to have both a specialist and a generalist skill set; a specialist without generalist skills will be ill equipped to deal with many of their patients. Osler's aphorism, "Care more particularly for the individual patient than for the especial features of the disease," is increasingly important. A holistic professional approach is essential. The shift back to maintaining generalism in the medical workforce, including initiatives such as Shape of Training, should accelerate and be given a greater focus in the selection, training, and reward of our future workforce.

Continued increases in healthy longevity depend on this different model. Clustering of diseases, and how we might better tackle management of coexisting physical and mental health problems, should be embedded into medical training and continuous professional development, including for specialists. Medical schools, the royal colleges, guideline groups, the General Medical Council, and the governments of the UK need to work together with the whole profession to tackle this. The pattern of health and disease in our population is changing, and as a profession we must respond.

Competing interests: We have read and understood BMJ policy on declaration of interests and have no relevant interests to declare.

Provenance and peer review: Commissioned; not externally peer reviewed.

1 Hardeep A. Multimorbidity: understanding the challenge. A report for the Richmond Group of Charities. 2018. https://richmondgroupofcharities.org.uk/sites/default/files/multimorbidity -_understanding_the_challenge.pdf

2 Barnett K, Mercer SW, Norbury M, Watt G, Wyke S, Guthrie B. Epidemiology of multimorbidity and implications for health care, research, and medical education: a cross-sectional study. Lancet 2012;380:37-43. 10.1016/S0140-6736(12)60240-2 22579043

3 Schiøtz ML, Stockmarr A, Høst D, Glümer C, Frølich A. Social disparities in the prevalence of multimorbidity. A register-based population study. BMC Public Health 2017;17:422. 10.1186/s12889-017-4314-8 28486983

4 Dunbar P, Hall M, Gay JC, etal . Hospital readmission of adolescents and young adults with complex chronic disease. JAMA Netw Open 2019;2:e197613. 10.1001/jamanetworkopen.2019.7613 31339547

5 Gaulin M, Simard M, Candas B, Lesage A, Sirois C. Combined impacts of multimorbidity and mental disorders on frequent emergency department visits: a retrospective cohort study in Quebec, Canada. CMAJ 2019;191:E724-32. 10.1503/cmaj.181712 31266786

6 Zhang R, Lu Y, Shi L, Zhang S, Chang F. Prevalence and patterns of multimorbidity among the elderly in China: a cross-sectional study using national survey data. BMJ Open 2019;9:e024268. 10.1136/bmjopen-2018-024268 31427309

7 Guthrie B, Payne K, Alderson P, McMurdo ME, Mercer SW. Adapting clinical guidelines to take account of multimorbidity. BMJ 2012;345:e6341. 10.1136/bmj.e6341 23036829

8 Academy of Medical Sciences. Multimorbidity: a priority for global health research. AMS, 2018.

Published by the BMJ Publishing Group Limited. For permission to use (where not already granted under a licence) please go to http://group.bmj.com/group/rights-licensing/ permissionshttp://creativecommons.org/licenses/by-nc/4.0/This is an Open Access article distributed in accordance with the Creative Commons Attribution Non Commercial (CC BY-NC 4.0) license, which permits others to distribute, remix, adapt, build upon this work non-commercially, and license their derivative works on different terms, provided the original work is properly cited and the use is non-commercial. See: http://creativecommons. org/licenses/by-nc/4.0\%. 